\section{P135 A NOVEL COMPOSITE INDEX FOR PROGNOSTIC STAGING OF COPD PATIENTS}

${ }^{1}$ AK Boutou, ${ }^{2}$ A Nair, ${ }^{3} \mathrm{R}$ Sandhu, ${ }^{4}$ DD Zadeh, ${ }^{5} \mathrm{DM}$ Hansell, ${ }^{6} \mathrm{AU}$ Wells, ${ }^{1} \mathrm{Ml}$ Polkey, ${ }^{1}$ NS Hopkinson; ${ }^{1}$ NIHR Respiratory Biomedical Research Unit, Royal Brompton and Harefield NHS Foundation Trust and Imperial College, London, UK; ${ }^{2}$ Department of Radiology, Royal Brompton Hospital, London, UK; ${ }^{3}$ Department of Radiology, Imperial College London, NHS Trust, London, UK; ${ }^{4}$ Department of Radiology, Chelsea and Westminster Hospital, London, UK; ${ }^{5}$ National Heart and Lung Institute, Imperial College London and Royal Brompton \& Harefield NHS Foundation Trust, London, UK; ${ }^{6}$ Interstitial Lung Disease Unit, Royal Brompton Hospital, London, UK

10.1136/thoraxjnl-2013-204457.285

Introduction Chronic Obstructive Pulmonary Disease (COPD) is characterised by high morbidity and mortality. Whether thorax computed tomography (CT)-derived parameters and lung function measurements carry more prognostic information individually or as a composite index has not yet been investigated.

Aim a) to compare the prognostic value of CT-determined emphysema and PAAo ratio versus various lung function parameters in a general COPD population and b) to construct a composite index for prognostic staging of COPD patients.

Material and Methods Predictors of mortality were assessed in a consecutive COPD outpatient population whose thorax CT, spirometry, lung volumes and gas transfer data were all collected prospectively in a clinical database. Univariate and multivariate Cox proportional Hazard analysis models were used and Hazard Ratios (HR) with corresponding 95\% Confidence Intervals (CI) were calculated. Survival data were available until April, 2013

Results 169 patients were included $(59.8 \%$ male, 61.1 years old). During the follow-up 20.1\% died; mean survival was 115.4 months. Age $(\mathrm{HR}=1.077 ; 95 \% \mathrm{Cl}=1.032-1.121)$ and emphysema score $(\mathrm{ES})(\mathrm{HR}=1.033 ; 95 \% \mathrm{CI}=1.010-1.057)$ were the only independent predictors of mortality when ES was treated as continuous variable in the multivariate regression. No association was found between PAAo Ratio and survival. Further analysis indicated that the 55\% threshold of ES could be used as optimal and the $30 \%$ and $65 \%$ thresholds as suboptimals for prognostic categorization of patients in "high" (ES $\geq 65 \%)$, "low" $(\mathrm{ES}<30 \%)$ and "intermediate" risk $(30 \% \geq \mathrm{ES}<65 \%)$ group. The TLC\%predicted was the most discriminatory of all pulmonary function parameters, so its threshold of 143\%, which

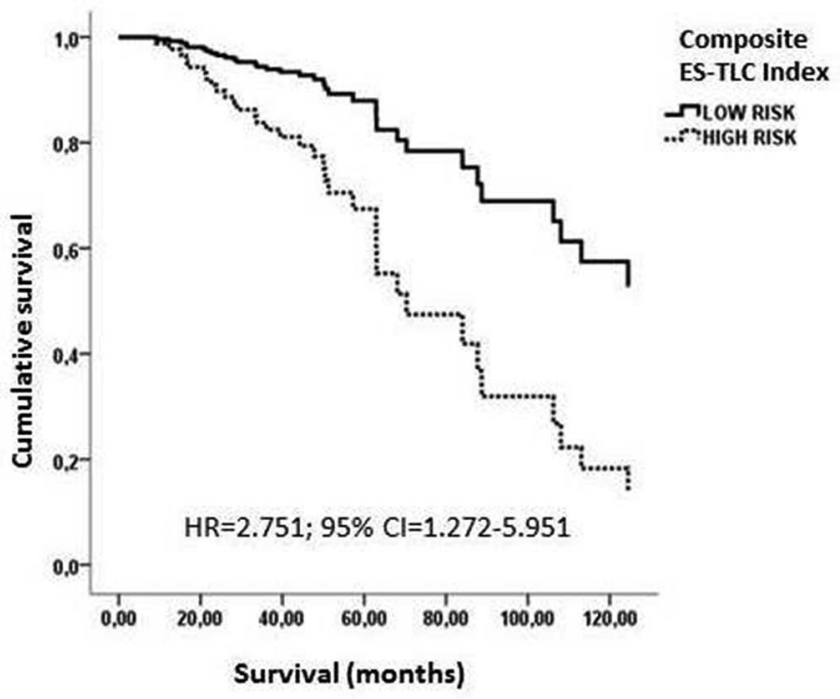

Abstract P135 Figure 1. The Es-TLC composite index for the prognostic categorization of COPD patients. corresponded to ES optimal threshold, was further applied for the construction of the index. The final composite index separated patients in "high" risk (ES $\geq 65 \%$ or TLC $>143 \%$ predicted for intermediate group) and "low" risk (ES $<30 \%$ or TLC $\leq 143 \%$ predicted for intermediate group) (Figure) and was more discriminatory $(\mathrm{HR}=2.751 ; 95 \% \mathrm{CI}=1.272-5.951)$ than any of its individual components.

Conclusion Although ES is better correlated with mortality than any pulmonary function parameter, a composite ES-TLC index carries the most prognostic information for COPD patients.

\section{P136 MULTIDIMENSIONAL PROGNOSTIC INDEX FOR EXACERBATIONS OF COPD}

${ }^{1} \mathrm{PM}$ Short, ${ }^{2} \mathrm{PA}$ Williamson, ${ }^{3} \mathrm{~A}$ Singanayagam, ${ }^{4} \mathrm{~A}$ Akram, ${ }^{1} \mathrm{~S}$ Schembri, ${ }^{1} \mathrm{JD}$ Chalmers; ${ }^{1}$ Ninewells Hospital, Dundee, UK; ${ }^{2}$ Perth Royal Infirmary, Perth, UK; ${ }^{3}$ Imperial College London, London, UK; ${ }^{4}$ Royal Infirmary of Edinburgh, Edinburgh, UK

\subsection{6/thoraxjn-2013-204457.286}

Introduction and Objectives Prognostic assessment of COPD exacerbations is currently limited by models that only take into account short term prognostic factors. We developed a multidimensional tool for COPD exacerbations, predicting both short and long term outcome.

Methods A prospective multicentre, UK observational cohort of patients hospitalised with exacerbations of COPD 2009-2011. Cox-proportional hazards regression used to identify independent predictors of 30-day and 1 year mortality. Two independent risk scores based on exacerbation severity (acute score) and severity of COPD and co-morbidities (chronic score) were developed. The two scores were then used to generate a 4 class decision grid based on the GOLD 2011 criteria for stable COPD.

Results 1343 patients were included. 749 patients were readmitted or died during 1 year follow-up.

Predictors of 30-day mortality (acute score) were new onset confusion HR 2.23 (95\%CI 1.34-3.71)- 1 point, Urea $>7 \mathrm{mmol} /$ L 2.64 (95\%CI 1.51-4.61)- 1 point, acidosis 4.22 (95\%CI 2.686.65)- 2 points, glucose $>8 \mathrm{mmol} / \mathrm{L} 1.5695 \% \mathrm{CI}$ (1.00-2.46)- 1 point and albumin $<35 \mathrm{~g} / \mathrm{L} 2.23(95 \%$ CI $1.42-3.5)-1$ point and heart rate $>110 \mathrm{bpm} 2.37$ (95\%CI $1.50-3.73)-1$ point. The

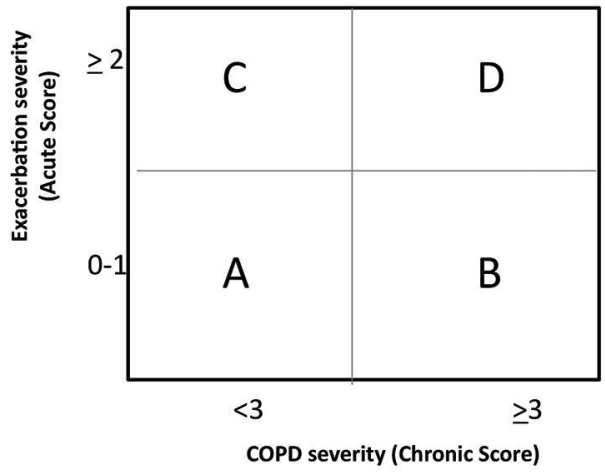

$\begin{array}{lllll} & \text { N } & \text { 30-day mortality } & \text { 1 year mortality } & \text { Readmissions } \\ \begin{array}{l}\text { Group A } \\ \text { (low short and long term risk) }\end{array} & 315 & 1(0.3 \%) & 13(4.1 \%) & 49(15.6 \%) \\ \begin{array}{l}\text { Group B } \\ \text { (moderate short term, high long term risk) }\end{array} & 201(1.0 \%) & 46(22.9 \%) & 131(65.1 \%) \\ \begin{array}{l}\text { Group C } \\ \text { (high short term, moderate long term risk) } \\ \text { Group D }\end{array} & 15(4.3 \%) & 32(9.2 \%) & 101(29.1 \%) \\ \text { (48) } & 64(13.3 \%) & 146(30.4 \%) & 280(58.3 \%)\end{array}$

Abstract P136 Figure 1. 